\title{
Evaluation of Rugby Players' Psychological-Competitive Ability by Utilizing the Analytic Hierarchy Process
}

\author{
Koichiro Aoki', Minoru Uehara ${ }^{2}$, Chieko Kato², Hiroyuki Hirahara1 \\ ${ }^{1}$ Graduate School of Science and Engineering, Saitama University, Saitama, Japan \\ ${ }^{2}$ Department of Information Sciences and Arts, Toyo University, Saitama, Japan \\ Email:s16dh001@mail.saitama-u.ac.jp
}

How to cite this paper: Aoki, K., Uehara, M., Kato, C. and Hirahara, H. (2016) Evaluation of Rugby Players' PsychologicalCompetitive Ability by Utilizing the Analytic Hierarchy Process. Open Journal of Social Sciences, 4, 103-117.

http://dx.doi.org/10.4236/jss.2016.412010

Received: November 15, 2016

Accepted: December 25, 2016

Published: December 29, 2016

Copyright $\odot 2016$ by authors and Scientific Research Publishing Inc. This work is licensed under the Creative Commons Attribution International License (CC BY 4.0).

http://creativecommons.org/licenses/by/4.0/ (c) $\underset{\mathrm{EY}}{\text { (i) Open Access }}$

\begin{abstract}
The Analytic Hierarchy Process (AHP) is a decision-making support method for selecting a solution from alternatives based on a number of evaluation criteria. This method has also been utilized in recent years to evaluate athletes' competitive ability regarding their physical, technical, and mental aspects. Therefore, this study has sought to develop an evaluation index of rugby players' psychological-competitive ability as their mental aspects. Initially, a survey on sixty-seven male university rugby players was conducted using the Diagnostic Inventory of Psychological-Competitive Ability (DIPCA.3) for Athletes. Next, a rugby coach was asked in an interview coach's to rank five factors of DIPCA.3. After that, total evaluation values of each rugby player were calculated using the DIPCA.3 scores, the coach's ranking, and AHP. The rugby players were divided into two groups, those with high or low DIPCA3 scores. Then, members in each of these two groups were divided again into two groups, for high or low total evaluation values of AHP. Comparing the high and low groups from the total evaluation values, the proportion of rugby players in the high level group, who were regular players and had much experience participating in national competitions, was significantly larger among the high group than the low group. The results of this study suggested that the total evaluation value calculated with AHP was more effective than the total scores of DIPCA.3 for evaluation of rugby players' mental aspects.
\end{abstract}

\section{Keywords}

Analytic Hierarchy Process, Diagnostic Inventory of Psychological-Competitive Ability for Athletes, Decision-Making Support, Rugby Players, Interview Survey

\section{Introduction}

As many have noted, in addition to the importance of spirit, technique, and physical 
strength in competitive sports, athletes require the ability to condition their mental states. Previous studies with a focus on the mental aspects of athletes have clarified the relationship between the characteristics of specific sporting events and players' personality traits [1], or between athletes' competition level and psychological-competitive ability (the psychological traits that are necessary for athletes to exert their performance in games) [2]. For example, Schurr, Ashley, and Joy (1977) reported that athletes' personality traits varied depending on whether the sporting events they played were individual competitions or team competitions [3]. Especially regarding team competitions in which each player's role is specialized in accordance with their positions, players' personality traits and psychological-competitive ability are also considered to be different among them.

Rugby is a sport in which a team consists of fifteen players, and each player has a specific role in accordance with their position. One previous study (Okamoto, Takatsu, and Terada, 1998) has shown that rugby player's characteristics of psychological-competitive ability varied among their positions [4]. A study on rugby coaches (Minouchi, 2013) has clarified the common psychological factors rugby players require, such as "Motivation", "Control of arousal level", "Courage and combative spirit", "Self-control", "comprehension", and "Sense of responsibility" [5]. These factors correspond to measurement items of Diagnostic Inventory of Psychological-Competitive Ability for Athletes (DIPCA.3). DIPCA.3 is a questionnaire for the measurement of athletes' psychological-competitive ability. Questionnaire surveys with a focus on the above five factors are said to be necessary to evaluate rugby players' mental aspects.

Calculating a total evaluation value that takes into account the importance of various types of skill is effective in evaluating athletes' ability quantitatively and comparing it among athletes. Maekawa et al. (2014) verified the validity of an evaluation scale of judo practitioners' competitive ability including technique, physical strength, and mental strength [6]. Their study adopted nine evaluation scales about competitive ability in judo, which is developed based on judo coaches' view. The Analytic Hierarchy Process (AHP) was used for calculating the total evaluation values of competitive ability from the nine evaluation scales. Judo practitioners' total evaluation values were strongly correlated to their rank in a judo competition, which indicates the validity of evaluation based on coaches' view and the evaluation values calculated with AHP.

As mentioned above, the previous study on rugby coaches has shown that there are the common psychological factors rugby players require. Because of that, rugby players' mental aspects can be evaluated more precisely with the evaluation method using AHP, which take account into rugby coaches' view. Therefore, this study adopted AHP for evaluation of rugby players' psychological-competitive ability and sought to calculate each player's total evaluation value. The players were divided into two groups depending on their scores on the questionnaire and total evaluation values, and the two groups were divided according to their years of experience playing rugby, the number of regular players, and their experience participating in national competitions. The purpose of this study was to verify the validity of the evaluation method for rugby players' psychological-competitive ability using AHP. 


\section{Method}

\subsection{Survey Method}

A questionnaire survey using DIPCA.3 was conducted on sixty-seven male rugby players belonging to the T-university rugby club (Average age: $19.31 \pm 1.05$ ). DIPCA.3 is the questionnaire for measurement of athletes' psychological-competitive ability, and consists of fifty-two question items, twelve subscales, and five factors (Table 1). Each subscale consists of four question items. Participants are asked to judge to what extent they usually apply to each question item describing various mental states in games (e.g., "I can perseveringly compete even in difficult situations"). Answers are scaled from one to five (" 1 almost never": $0 \%$ - 10\%, " 2 rarely": $25 \%$, " 3 sometimes": $50 \%$, " 4 frequently": 70\%, "5 always": 100\%). Scores from the twelve subscales were calculated from the summary values of each participant's answer, and the scores of five factors were calculated from the twelve subscales. The scores of five factors can be rated on a scale of one to five (1: very low score - 5: very high score) in accordance with gender-segregated evaluation criteria (Table 2: "The profile of psychological-competitive ability by each factor").

This study evaluated each rugby player's factor scores calculated from their answers according to the profile of psychological-competitive ability by each factor. In addition, the answers to three question items about the participants themselves in DIPCA.3 (years of experience in Rugby: 1 - 4 years, 5 - 9 years, more than 10 years; whether they were regular players or not; experience participating in national competitions: none, 1 2 times, more than 3 times) were totaled up, which may be related to their competition level.

Following this, an interview survey with a male rugby coach from the T-university

Table 1. Twelve subscales and five factors of DIPCA.3.

\begin{tabular}{|c|c|c|}
\hline Five factors & Twelve subscales & Example of question items \\
\hline \multirow{4}{*}{ Volition for competition } & Patience & I can perseveringly compete even in difficult situations. \\
\hline & Aggressiveness & $\begin{array}{l}\text { The more major the game I'm in, the greater fighting } \\
\text { spirit I have. }\end{array}$ \\
\hline & $\begin{array}{l}\text { Volition for } \\
\text { self-realization }\end{array}$ & $\begin{array}{l}\text { I compete with the attitude of going to the limits of my } \\
\text { abilities. }\end{array}$ \\
\hline & Volition for winning & Before a game, I think "I'm not going to lose". \\
\hline \multirow{3}{*}{$\begin{array}{l}\text { Mental stability and } \\
\text { concentration }\end{array}$} & Self-control & I'm not able to control myself whenever there is a game. \\
\hline & Ability to relax & I get nervous worring too much about winning or losing. \\
\hline & Concentration & I'm unable to make calm moves. \\
\hline \multirow[t]{2}{*}{ Confidence } & Confidence & $\begin{array}{l}\text { I have confidence I can display my abilities even under } \\
\text { pressure. }\end{array}$ \\
\hline & Decision & I can make decisive moves just at the right time. \\
\hline \multirow{2}{*}{ Strategic ability } & Predictive ability & Every strategy of mine proves successful. \\
\hline & Judgement & I am a person of sound judgment. \\
\hline Cooperation & Cooperation & I value teamwork. \\
\hline
\end{tabular}


Rugby club was conducted, and he was asked to rank the importance of the five factors of DIPCA.3 for rugby players' performance in games.

\subsection{Analysis Method}

1) Cross tabulation between questionnaire items

Concerning the sixty-seven Rugby players, cross tabulation and chi-square tests were carried out among three question items on the DIPCA.3 (years of experience in rugby, whether they were regular players or not, and experience participating in national competitions).

2) Calculation of total evaluation values

The results of the questionnaire survey were analyzed using the AHP method while calculating total scores of DIPCA.3 in order to acquire a comprehensive evaluation index of rugby players' mental aspects. AHP (Analytic Hierarchy Process) is the decision-making support method advocated by Saaty (1980) with which a total evaluation value for selecting a solution from alternatives can be calculated based on a number of evaluation criteria and subjective decisions [7]. When using the AHP, initially it is necessary to clarify "Goal" (which is the final goal in the decision-making situation), "Alternatives" (from which a solution is selected), and "Criteria" (which is the criteria for selecting a solution), and to make a hierarchy as seen in Figure 1. This study regarded

Table 2. The profile of psychological-competitive ability by each factor.

\begin{tabular}{|c|c|c|c|c|c|c|c|c|c|}
\hline \multicolumn{2}{|c|}{ Factor } & \multicolumn{2}{|c|}{ Gender } & 1 very low & \multicolumn{2}{|c|}{2 a little low } & 3 not quite & 4 a little high & 5 very high \\
\hline \multirow{2}{*}{\multicolumn{2}{|c|}{ Volition for competition }} & \multicolumn{2}{|c|}{ male } & $16-51$ & \multicolumn{2}{|c|}{$52-60$} & $61-70$ & $71-75$ & $76-80$ \\
\hline & & \multicolumn{2}{|c|}{ female } & $16-47$ & \multicolumn{2}{|c|}{$48-57$} & $58-66$ & $67-76$ & $77-80$ \\
\hline \multirow{2}{*}{\multicolumn{2}{|c|}{$\begin{array}{l}\text { Mental stability } \\
\text { and concentration }\end{array}$}} & \multirow{2}{*}{\multicolumn{2}{|c|}{$\begin{array}{l}\text { male } \\
\text { female }\end{array}$}} & $12-29$ & \multicolumn{2}{|c|}{$30-39$} & $40-48$ & $49-58$ & $59-60$ \\
\hline & & & & $12-29$ & \multicolumn{2}{|c|}{$30-37$} & $38-46$ & $47-55$ & $56-60$ \\
\hline \multirow{2}{*}{\multicolumn{2}{|c|}{ Confidence }} & \multirow{2}{*}{\multicolumn{2}{|c|}{$\begin{array}{l}\text { male } \\
\text { female }\end{array}$}} & $8-17$ & \multicolumn{2}{|c|}{$18-23$} & $24-30$ & $31-37$ & $38-40$ \\
\hline & & & & $8-14$ & \multicolumn{2}{|c|}{$15-20$} & $21-26$ & $27-32$ & $33-40$ \\
\hline \multirow{2}{*}{\multicolumn{2}{|c|}{ Strategic ability }} & \multirow{2}{*}{\multicolumn{2}{|c|}{$\begin{array}{l}\text { male } \\
\text { female }\end{array}$}} & $8-16$ & \multicolumn{2}{|c|}{$17-22$} & $23-29$ & $30-35$ & $36-40$ \\
\hline & & & & $8-14$ & \multicolumn{2}{|c|}{$15-19$} & $20-25$ & $26-31$ & $32-40$ \\
\hline \multirow{2}{*}{\multicolumn{2}{|c|}{ Cooperation }} & \multirow{2}{*}{\multicolumn{2}{|c|}{$\begin{array}{l}\text { male } \\
\text { female }\end{array}$}} & $4-12$ & & & $16-18$ & 19 & 20 \\
\hline & & & & $4-12$ & & & $16-18$ & 19 & 20 \\
\hline Goal & & & & $\begin{array}{l}\text { To select } \\
\text { psych }\end{array}$ & $\begin{array}{l}\text { a Ru } \\
\text { logic }\end{array}$ & $\begin{array}{l}\text { y play } \\
\text { comp }\end{array}$ & $\begin{array}{l}\text { er who ha } \\
\text { etitive ab }\end{array}$ & $\begin{array}{l}\text { high } \\
\text { lity }\end{array}$ & \\
\hline Criteria & $\begin{array}{l}\text { Volition } \\
\text { competi }\end{array}$ & & $\begin{array}{r}\mathrm{M} \\
\text { and }\end{array}$ & $\begin{array}{l}\text { ental stab } \\
\text { concentr }\end{array}$ & $\begin{array}{l}\text { lity } \\
\text { tion }\end{array}$ & Con & idence & $\begin{array}{c}\text { Strategic } \\
\text { ability }\end{array}$ & Cooperation \\
\hline Alternatives & & & & sixty- & seven & ale & ugby pla & & \\
\hline
\end{tabular}

Figure 1. Hierarchy of AHP in this study. 
five factors of DIPCA.3 as Criteria in order to select rugby players who had high psychological-competitive ability from among sixty-seven players (Alternatives).

Next, as a general rule, the degree of importance for each one of Criteria and Alternatives are calculated based on results of paired comparison between Criteria or Alternatives. In the paired comparison method, participants are asked to select a criterion that is more important than another, or a solution that is preferable to others. Because participants compare all combinations of Criteria or Alternatives, in the situation depicted in Figure 1, they need to select a criterion ten times, and select a solution two thousand two hundred eleven times. In this study, the method by which degrees of importance for each one of Criteria and Alternatives are calculated based on the interview and questionnaire survey in order to reduce such burdens of paired comparison.

The results of ranking five criteria by the rugby coach were adapted to the results of paired comparison. The paired comparison method in AHP usually asked participants to indicate to what extent a criterion (Reference) is more important than another (Comparison) on a scale of one to nine (1/5: Comparison is more important overwhelmingly - 5: Reference is more important overwhelmingly). Therefore, this study regarded the difference of the ranking between Criteria as the difference in the degree of importance between them, and converted the difference into numerical values from one-fifth to five. If "Strategic ability", which is the third-ranking factor of DIPCA.3, is regarded as Reference, "Strategic ability" is considered to be two ranks more important than "Cooperation" which is the fifth-ranking factor (Figure 2). That is, the difference in the degree of importance between them is three. In the same way, if "Cooperation" is regarded as Reference, "Cooperation" is considered to be four ranks less important than "Volition for Competition", which is the first-ranking factor, and the difference in the degree of importance between them is one-fifth.

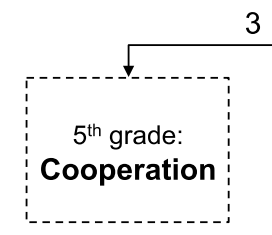

Comparison
3

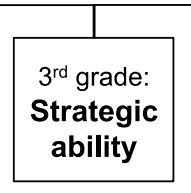

Reference
$1 / 3$

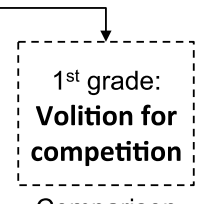

Comparison

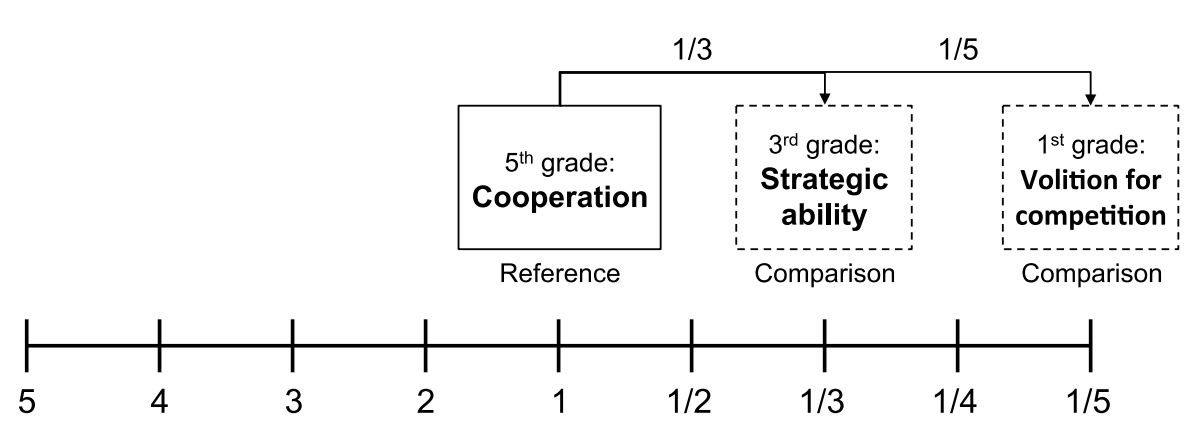

: Reference is more important overwhelmingly

Figure 2. Interpretation method about ranking by coach. 
Each rugby player's rated values of five factors calculated from the questionnaire results were also adapted to the results of paired comparison. The difference in the rated values between two players was regarded as the difference of the importance degrees between them, and was converted into numerical values from one-fifth to five.

The importance degrees of each one of Criteria and Alternatives were acquired by calculating the difference among the degrees of importance between five Criteria or sixty-seven Alternatives and making a paired comparison table (see below). The total evaluation values for each rugby player were calculated by summing up five values of the importance degrees of each one of sixty-seven Alternatives multiplied by the importance degrees of five Criteria.

3) Comparison between total scores of DIPCA.3 and total evaluation values of AHP

Among sixty-seven rugby players, the top twenty players who got high total scores for the five factor scores of DIPCA.3 were classified into the high group of DIPCA.3, and the bottom twenty players who got low total scores were classified into the low group of DIPCA.3. In a similar way, the top twenty players who got high total evaluation values on the AHP were classified into the high group of AHP, and the bottom twenty players who got low total evaluation values on the AHP were classified into the low group of AHP. The answers to three question items about the participants themselves in DIPCA.3 (years of experience in rugby, whether they were regular players or not, and experience participating in national competitions) were totaled up in each group. The proportion of these answers was compared between the high and low groups of DIPCA.3 and between those of AHP using the qui square test.

In addition, forty rugby players, classified into high and low groups of DIPCA.3 or AHP, were divided into two positions (Forwards: FW or Backs: BK). After that, the answers to three question items (years of experience in rugby, whether they were regular players or not, and experience participating in national competitions) were totaled up for each position. The proportion of these answers by players in each position was compared between the high and low groups of DIPCA.3 and between those of AHP using the qui square test.

\section{Results}

\subsection{Results of Cross Tabulation among Questionnaire Items}

The results of cross tabulation among three questionnaire items are shown in Table 3.

The results of the qui square test showed a significant difference only between whether they were regular players or not and the experience participating in national competitions $(\mathrm{p}<0.05)$. The proportion of the players who had much experience participating in national competitions (more than three times) was larger among the regular players than the others.

\subsection{Degrees of Importance for Each Criterion}

The interview survey with the rugby coach showed that five factors of DIPCA.3 are important for rugby players, in the order of: Volition for competition, Mental stability 
Table 3. Cross tabulation between questionnaire items.

(a)

\begin{tabular}{ccc}
\hline Years of experience in Rugby & Regular players & Not regular players \\
\hline 1 - 4 years & 1 & 8 \\
& $(6.7 \%)$ & $(15.4 \%)$ \\
5 - 9 years & 7 & 28 \\
& $(46.7 \%)$ & $(53.8 \%)$ \\
more than 10 years & 7 & 16 \\
qui square test & $(46.7 \%)$ & n.s. \\
\hline
\end{tabular}

(b)

\begin{tabular}{|c|c|c|}
\hline Experience participating national competitions & Regular players & Not regular players \\
\hline \multirow{2}{*}{ nothing } & 1 & 17 \\
\hline & $(6.7 \%)$ & $(32.7 \%)$ \\
\hline \multirow{2}{*}{$1-2$ times } & 5 & 24 \\
\hline & $(33.3 \%)$ & $(46.2 \%)$ \\
\hline \multirow{2}{*}{ more than 3 times } & 9 & 11 \\
\hline & $(60.0 \%)$ & $(21.2 \%)$ \\
\hline qui square test & \multicolumn{2}{|c|}{${ }^{* *}(\mathrm{p}<0.01)$} \\
\hline
\end{tabular}

(c)

\begin{tabular}{cccc}
\hline \multirow{2}{*}{ Experience participating national competitions } & \multicolumn{3}{c}{ Years of experience in Rugby } \\
\cline { 2 - 4 } nothing & $1-4$ years & $5-9$ years & more than 10 years \\
\hline \multirow{2}{*}{1 - 2 times } & $(33.3 \%)$ & $(28.6 \%)$ & 5 \\
& 6 & 15 & 8 \\
more than 3 times & $(66.7 \%)$ & $(42.9 \%)$ & $(34.8 \%)$ \\
qui square test & 0 & 10 & 10 \\
\hline
\end{tabular}

and concentration, Strategic ability, Confidence, and Cooperativeness. The paired comparison table based on the results of ranking and the degrees of importance for each one of Alternatives is shown in Table 4.

This study calculated five geometric mean values of five values on a same line in Table 3. The importance degrees of each one of Alternatives were calculated by means of dividing the geometric mean values on each line by a total value of them.

Regarding Alternatives, paired comparison tables were made in a similar way for each criterion and five importance degrees per rugby player were calculated.

\subsection{Comparison between High Group and Low Group of Total Scores of DIPCA.3}

Regarding the high and low groups of DIPCA.3, the results of totaling up the answers to the questions about the years of experience in rugby, whether they were regular 
players or not, and the experience participating in national competitions, are shown in

Table 5.

Table 4. Paired comparison table of criteria.

\begin{tabular}{ccccccc}
\hline $\begin{array}{c}\text { Psychological-competitive } \\
\text { ability }\end{array}$ & $\begin{array}{c}\text { Volition for } \\
\text { competition }\end{array}$ & $\begin{array}{c}\text { Mental stability } \\
\text { and concentration }\end{array}$ & $\begin{array}{c}\text { Confidence } \\
\text { Strategic } \\
\text { ability }\end{array}$ & $\begin{array}{c}\text { Cooperation } \\
\text { degree }\end{array}$ \\
\hline $\begin{array}{c}\text { Volition for competition } \\
\text { Mental stability and }\end{array}$ & 1 & 2 & 4 & 3 & 5 & 0.42 \\
$\begin{array}{c}\text { concentration } \\
\text { Confidence }\end{array}$ & $1 / 2$ & 1 & 3 & 2 & 4 & 0.26 \\
$\begin{array}{c}\text { Strategic ability } \\
\text { Cooperation }\end{array}$ & $1 / 4$ & $1 / 3$ & 1 & $1 / 2$ & 2 & 0.10 \\
\hline
\end{tabular}

Table 5. Comparison between high and low group of DIPCA.3.

(a)

\begin{tabular}{ccc}
\hline \multirow{2}{*}{ Years of experience in Rugby } & \multicolumn{2}{c}{ DIPCA.3 } \\
\cline { 2 - 3 } & High group $(\mathrm{n}=20)$ & Low group $(\mathrm{n}=20)$ \\
\hline \multirow{2}{*}{ - 4 years } & 2 & 5 \\
& $(10.0 \%)$ & $(25.0 \%)$ \\
5 - 9 years & 5 & 12 \\
& $(25.0 \%)$ & $(60.0 \%)$ \\
More than 10 years & 13 & 3 \\
Qui square test & $(65.0 \%)$ & $(15.0 \%)$ \\
\hline
\end{tabular}

(b)

\begin{tabular}{ccc}
\hline \multirow{2}{*}{ Regular/not regular players } & \multicolumn{2}{c}{ DIPCA.3 } \\
\cline { 2 - 3 } & High group $(\mathrm{n}=20)$ & Low group $(\mathrm{n}=20)$ \\
\hline \multirow{2}{*}{ Regular } & 6 & 1 \\
& $(30.0 \%)$ & $(5.0 \%)$ \\
Not regular & 14 & 19 \\
Qui square test & $(70.0 \%)$ & $(95.0 \%)$ \\
\hline
\end{tabular}

(c)

\begin{tabular}{ccc}
\hline \multirow{2}{*}{ Experience participating national competitions } & \multicolumn{2}{c}{ DIPCA.3 } \\
\cline { 2 - 3 } & High group $(\mathrm{n}=20)$ & Low group $(\mathrm{n}=20)$ \\
\hline \multirow{2}{*}{ Nothing } & 5 & 8 \\
& $(25.0 \%)$ & $(40.0 \%)$ \\
$1-2$ times & 7 & 10 \\
& $(35.0 \%)$ & $(50.0 \%)$ \\
More than 3 times & 8 & 2 \\
Qui square test & $(40.0 \%)$ & $(10.0 \%)$ \\
& & n.s. \\
\hline
\end{tabular}


The results of the qui square tests showed that there was a significant difference between the high and low groups of DIPCA.3 only with regard to their years of experience in rugby $(\mathrm{p}<0.01)$. The proportion of the players, who had many years of experience in rugby, was larger in the high group than in the low group.

\subsection{Comparison between High Group and Low Group of Total Evaluation Values of AHP}

Regarding the high and low groups of AHP, the results of totaling up the answers to the questions about the years of experience in rugby, whether they were regular players or not, and the experience participating in national competitions are shown in Table 6.

Table 6. Comparison between high and low group of AHP.

(a)

\begin{tabular}{|c|c|c|}
\hline \multirow{2}{*}{ Years of experience in Rugby } & \multicolumn{2}{|c|}{ AHP } \\
\hline & High group $(\mathrm{n}=20)$ & Low group $(n=20)$ \\
\hline \multirow{2}{*}{$1-4$ years } & 1 & 5 \\
\hline & $(5.0 \%)$ & $(25.0 \%)$ \\
\hline \multirow{2}{*}{$5-9$ years } & 6 & 12 \\
\hline & $(30.0 \%)$ & $(60.0 \%)$ \\
\hline \multirow{2}{*}{ More than 10 years } & 13 & 3 \\
\hline & $(65.0 \%)$ & $(15.0 \%)$ \\
\hline Qui square test & \multicolumn{2}{|c|}{${ }^{*}(\mathrm{p}<0.01)$} \\
\hline
\end{tabular}

(b)

\begin{tabular}{ccc}
\hline \multirow{2}{*}{ Regular/not regular players } & \multicolumn{2}{c}{ AHP } \\
\cline { 2 - 3 } Regular & High group $(\mathrm{n}=20)$ & Low group $(\mathrm{n}=20)$ \\
& 7 & 1 \\
Not regular & $(35.0 \%)$ & $(5.0 \%)$ \\
Qui square test & 13 & $(95.0 \%)$ \\
& $(65.0 \%)$ & \\
\hline
\end{tabular}

(c)

\begin{tabular}{ccc}
\hline \multirow{2}{*}{ Experience participating national competitions } & \multicolumn{2}{c}{ AHP } \\
\cline { 2 - 3 } Nothing & High group $(\mathrm{n}=20)$ & Low group $(\mathrm{n}=20)$ \\
& 4 & 7 \\
1 - 2 times & $(20.0 \%)$ & $(35.0 \%)$ \\
& 6 & $(55.0 \%)$ \\
More than 3 times & $(30.0 \%)$ & 2 \\
Qui square test & $(50.0 \%)$ & $(10.0 \%)$ \\
\hline
\end{tabular}


The results of the qui square tests showed a significant difference between the high and low groups of AHP regarding the years of experience in rugby $(\mathrm{p}<0.01)$, whether they were regular players or not $(\mathrm{p}<0.05)$, and the experience participating in national competitions $(\mathrm{p}<0.05)$. The proportion of the regular players, who had many years of experience in rugby and many experiences participating in national competitions, was larger in the high group than in the low group.

\subsection{Comparison of Players in Each Position between High Group and Low Group of Total Scores of DIPCA.3}

Regarding the FW players and BK players in the high and low groups of DIPCA.3, the results of totaling up the answers to the questions about years of experience in rugby, whether they were regular players or not, and experience participating in national competitions, are shown in Table 7.

Table 7. Comparison between high and low group of DIPCA.3 (by each position).

(a)

\begin{tabular}{ccccc}
\hline \multirow{2}{*}{$\begin{array}{c}\text { Years of experience in } \\
\text { Rugby }\end{array}$} & $\begin{array}{c}\text { FW players } \\
\text { DIPCA.3 high group } \\
(\mathrm{n}=9)\end{array}$ & $\begin{array}{c}\text { DIPCA.3 low group } \\
(\mathrm{n}=11)\end{array}$ & $\begin{array}{c}\text { DIPCA.3 high group } \\
(\mathrm{n}=11)\end{array}$ & $\begin{array}{c}\text { DIPCA.3 low group } \\
(\mathrm{n}=9)\end{array}$ \\
\hline \multirow{2}{*}{1 - 4 years } & 1 & 5 & 1 & 0 \\
& $(11.1 \%)$ & $(45.5 \%)$ & $(9.1 \%)$ & $(0.0 \%)$ \\
5 - 9 years & 3 & 4 & 2 & $(88.9 \%)$ \\
& $(33.3 \%)$ & $(36.4 \%)$ & $(18.2 \%)$ & 1 \\
More than 10 years & 5 & 2 & 8 & $(11.1 \%)$ \\
Qui square test & $(55.6 \%)$ & & $(18.2 \%)$ & \multicolumn{2}{c}{$*{ }^{* *}(\mathrm{p}<0.01)$} \\
\hline
\end{tabular}

(b)

\begin{tabular}{ccccc}
\hline \multirow{2}{*}{\begin{tabular}{c} 
Regular/not regular $\begin{array}{c}\text { FW players } \\
\text { players }\end{array}$ \\
\cline { 2 - 5 }
\end{tabular}} & $\begin{array}{c}\text { DIPCA.3 high group } \\
(\mathrm{n}=9)\end{array}$ & $\begin{array}{c}\text { DIPCA.3 low group } \\
(\mathrm{n}=11)\end{array}$ & $\begin{array}{c}\text { DIPCA.3 high group } \\
(\mathrm{n}=11)\end{array}$ & $\begin{array}{c}\text { DIPCA.3 low group } \\
(\mathrm{n}=9)\end{array}$ \\
\hline Regular & 2 & 0 & 3 & 1 \\
& $(22.2 \%)$ & $(0.0 \%)$ & $(27.3 \%)$ & $(11.1 \%)$ \\
Not regular & 7 & 11 & 8 & 8 \\
Qui square test & $(77.8 \%)$ & $(100.0 \%)$ & $(72.7 \%)$ & $(88.9 \%)$ \\
\hline
\end{tabular}

(c)

\begin{tabular}{ccccc}
\hline \multirow{2}{*}{$\begin{array}{c}\text { Experience participating } \\
\text { national competitions }\end{array}$} & \multicolumn{2}{c}{ FW players } & \multicolumn{2}{c}{ BK players } \\
\cline { 2 - 5 } & $\begin{array}{c}\text { DIPCA.3 high group DIPCA.3 low group DIPCA.3 high group DIPCA.3 low group } \\
(\mathrm{n}=9)\end{array}$ & $(\mathrm{n}=11)$ & $\begin{array}{c}(\mathrm{n}=11) \\
(\mathrm{n}=9)\end{array}$ \\
\hline Nothing & 3 & $46.4 \%$ & $18.2 \%$ & 4 \\
& $33.3 \%$ & 6 & 5 & $44.4 \%$ \\
1 - 2 times & 2 & $54.5 \%$ & $45.5 \%$ & 4 \\
& $22.2 \%$ & 1 & 4 & 1 \\
More than 3 times & 4 & $9.1 \%$ & $36.4 \%$ & $11.1 \%$ \\
Qui square test & $44.4 \%$ & & & n.s. \\
\hline
\end{tabular}


The results of the qui square tests showed that there was a significant difference only between the BK players in the high and low groups of DIPCA.3 with regard to their years of experience in rugby $(\mathrm{p}<0.01)$. The proportion of the BK players, who had many years of experience in rugby, was larger in the high group than in the low group.

\subsection{Comparison of Players in Each Position between High Group and Low Group of Total Evaluation Values of AHP}

Regarding the FW players and BK players in the high and low groups of AHP, the results of totaling up the answers to the questions about years of experience in rugby, whether they were regular players or not, and their experience participating in national competitions, are shown in Table 8.

Table 8. Comparison between high and low group of AHP (by each position).

(a)

\begin{tabular}{ccccc}
\hline \multirow{2}{*}{$\begin{array}{c}\text { Years of experience in } \\
\text { Rugby }\end{array}$} & $\begin{array}{c}\text { FHP high group } \\
(\mathrm{n}=9)\end{array}$ & $\begin{array}{c}\text { AHP low group } \\
(\mathrm{n}=10)\end{array}$ & $\begin{array}{c}\text { AHP high group } \\
(\mathrm{n}=11)\end{array}$ & $\begin{array}{c}\text { AHP low group } \\
(\mathrm{n}=10)\end{array}$ \\
\cline { 2 - 5 } 1 - 4 years & 0 & 4 & 1 & 1 \\
& $0.0 \%$ & $40.0 \%$ & $9.1 \%$ & $10.0 \%$ \\
5 - 9 years & 3 & 4 & 3 & $80.0 \%$ \\
& $33.3 \%$ & $40.0 \%$ & $27.3 \%$ & 1 \\
More than 10 years & 6 & 2 & 7 & $10.0 \%$ \\
Qui square test & $66.7 \%$ & $20.0 \%$ & $63.6 \%$ & $*(\mathrm{p}<0.05)$ \\
\hline
\end{tabular}

(b)

\begin{tabular}{ccccc}
\hline \multirow{2}{*}{ Regular/not regular players } & \multicolumn{2}{c}{ FW players } & \multicolumn{2}{c}{ BK players } \\
\cline { 2 - 5 } & $\begin{array}{c}\text { AHP high group } \\
(\mathrm{n}=9)\end{array}$ & $\begin{array}{c}\text { AHP low group } \\
(\mathrm{n}=10)\end{array}$ & $\begin{array}{c}\text { AHP high group } \\
(\mathrm{n}=11)\end{array}$ & $\begin{array}{c}\text { AHP low group } \\
(\mathrm{n}=10)\end{array}$ \\
\hline Regular & 4 & 0 & 3 & 1 \\
Not regular & $44.4 \%$ & $0.0 \%$ & $27.3 \%$ & $10.0 \%$ \\
Qui square test & 5 & 10 & 8 & 9 \\
\hline
\end{tabular}

(c)

\begin{tabular}{ccccc}
\hline \multirow{2}{*}{$\begin{array}{c}\text { Experience participating national } \\
\text { competitions }\end{array}$} & \multicolumn{2}{c}{ FW players } & \multicolumn{2}{c}{ BK players } \\
\cline { 2 - 5 }$(\mathrm{n}=9)$ & 2 & $\begin{array}{c}\text { AHP high group } \\
(\mathrm{n}=10)\end{array}$ & $\begin{array}{c}\text { AHP low group } \\
(\mathrm{n}=11)\end{array}$ & $\begin{array}{c}\text { AHP high group group } \\
(\mathrm{n}=10)\end{array}$ \\
\hline Nothing & $22.2 \%$ & $30.0 \%$ & $18.2 \%$ & 4 \\
& 1 & 6 & 5 & $40.0 \%$ \\
$1-2$ times & $11.1 \%$ & $60.0 \%$ & $45.5 \%$ & $50.0 \%$ \\
More than 3 times & 6 & 1 & 4 & 1 \\
Qui square test & $66.7 \%$ & $10.0 \%$ & $36.4 \%$ & $10.0 \%$ \\
\hline
\end{tabular}


Regarding both FW and BK players, the results of the qui square tests showed a significant difference in the years of experience in rugby $(\mathrm{p}<0.05)$ between the high and low groups of AHP. With regard to whether they were regular players or not $(\mathrm{p}<0.05)$ and whether they had experience participating in national competitions $(\mathrm{p}<0.05)$, there was a significant difference only between the FW players in the high and low groups. The proportion of the FW and BK players, who had many years of experience in rugby, was larger in the high group than in the low group. The proportion of the FW players, who were regular and had many experiences participating in national competitions, was also larger in the high group than in the low group.

\section{Discussion}

From the results of cross tabulation, it was confirmed that the regular players had more experiences of participating in national competitions than the other players. Being selected as a regular player and getting many opportunities to participate national competitions can be regarded as indexes indicating rugby players' competition levels. In contrast, there was no significant difference depending on the years of experience in rugby, which suggested that having many years of experience in rugby is not necessarily related to a high competition level.

Comparing the high and low group of DIPCA.3, the proportion of players who had many years of experience in rugby is larger in the high group than in the low group. Comparing the high and low groups of AHP, in contrast, the proportion of the regular players who have not only many years of experience but also much experience participating in national competitions, is larger in the high group than in the low group. Therefore, it is said that the players who had higher competition levels could be selected as the high group by dividing the rugby players into two groups depending on the total evaluation values of AHP.

Moreover, this study carried out the analysis with a focus on the players' positions (Forwards: FW or Backs: BK). Calculating the proportion of answers in each position and comparing it between the high and low groups of DIPCA.3, there was a significant difference regarding the BK players' years of experience in rugby. On the other hand, there was significant difference regarding both FW and BK players' years of experience when comparing the proportion of answers between the high and low groups of AHP. The results also showed a significant difference regarding the number of regular FW players and their experience participating in national competitions between the high and low groups of AHP. It is said that the regular FW players with great experience were classified into the high group when they were evaluated by means of AHP. Therefore, AHP may be particularly suitable for evaluation of the FW players.

Concerning the reason why the results of grouping of the rugby players based on total evaluation values were in accordance with their competition levels, the relationship between athletes' competition levels and psychological-competitive ability can be cited. This relationship was confirmed in many previous researches. Regarding rugby players, people whose competition levels were high had higher scores on the DIPCA.3 than others (Okamoto, Takatsu, and Terada, 1998) [5]. In this study, the calculation of total 
evaluation value using AHP confirmed the scores of DIPCA.3 reflected in the rugby coach's view, and made it possible to evaluate rugby players' psychological-competitive ability more accurately. Given that athletes' competition levels are related to their mental aspects, development of an accurate evaluation method of rugby players' psychological-competitive ability resulted in the improvement of prediction accuracy for their competition levels.

The interview with the rugby coach has clarified the importance of Volition for competition and Mental stability and concentration as psychological-competitive abilities rugby players require. These abilities can be associated with such psychological factors as "Motivation", "Control of arousal level", "Courage and combative spirit", "Self-control", and "Sense of responsibility", all of which have been mentioned in the previous research (Minouchi, 2013) [6], and they are essential for rugby players to exert their performance and win as a team. Applying the coach's view in this manner to the calculation of the degrees of importance of Alternatives in AHP is considered to make it possible to evaluate Rugby players' psychological-competitive ability more accurately.

The analysis about each position indicated that the high competition level of the FW players was reflected in the total evaluation values of AHP more prominently than the total scores of DIPCA.3. On the other hand, there was no prominent difference in the evaluation results of the BW players between the total scores of DIPCA.3 and the total evaluation values of AHP. Considering that AHP could evaluate not only the FW players' psychological-competitive ability but also their competition level more precisely, this evaluation method may be more effective for the FW players than the BK players. In order to take a ball from an opponent, the FW players often experience physical contact, such as scrums and tackles, in rugby games. Therefore, they are considered to require aggressiveness to overcome the fear of physical contact as well as self-control to maintain relaxed attitude and concentration depending on the situation. That is, it is important for the FW players to have the psychological-competitive ability such as "Volition for competition" and "Mental stability and concentration". The rugby coach also considered that this ability is important for rugby, and his view was incorporated into the evaluation using AHP. As a result, the FW players who had high competition levels might be highly evaluated by means of AHP.

The results of this study showed that the evaluation method using AHP, which take account into the rugby coach's view, is more proper for the evaluation of the rugby players' mental aspects, especially for the FW players, than the only usage of DIPCA.3. However, there is still room for consideration about evaluation method corresponding to each player's position. And also, this study calculated the total evaluation values only from the rugby players' scores of the DIPCA.3. In future, it is necessary to carry out many kinds of psychological tests. Using scores of various psychological tests as evaluation criteria in AHP can enable to grasp more aspects of rugby players' mind and evaluate them more precisely.

\section{Conclusions}

Based on the questionnaire and interview surveys with the rugby club, this study sought 
to calculate a more accurate evaluation index of rugby players' psychological-competitive ability using the method of AHP. The purpose of this study was to verify the relationship between the high and low of rugby players' total evaluation values and their years of experience in rugby, whether they were regular players or not, and their experience participating in national competitions. The results of this study suggested that the total evaluation value calculated using AHP reflected the rugby players' psychological competitive ability and competition level more accurately. By calculating degrees of importance for questionnaire items and scores in accordance with AHP as the method advocated in this study, one may anticipate acquiring a more valid evaluation index of measuring objects.

The analysis about each position showed that the evaluation using AHP is more effective for FW players than BK players. The calculation for the degree of importance for each factor among the psychological-competitive ability was considered particularly to reflect the role of the FW players in rugby games. Regarding the BK players, they may require different factors among the psychological-competitive abilities. These results suggested that the evaluation of athletes using AHP requires consideration about the role of each player's position.

This study treated only five factors of DIPCA.3 as Alternatives in AHP for the calculation of the total evaluation value of psychological-competitive ability. In future, surveys covering various psychological factors, such as personality traits, mood states, stress, and motivation, will be conducted in order to calculate a comprehensive evaluation index about athletes' mental aspects. Eventually, it is hoped that an index for grasping athletes' spirit, technique, and physical strength comprehensively will be developed with an analysis utilizing biological data about the physical and technical aspects of sports.

\section{References}

[1] Clingman, J.M. and Hilliard, D.V. (1987) Some Personality Characteristics of the Super-Adherer: Following Those Who Go Beyond Fitness. Journal of Sport Behavior, 10, 123 136.

[2] Tokunaga, M., Yoshida, E., Shigeeda, T., Azuma, K., Inadomi, T. and Saito, T. (2000) Differences between the Sexes, Competitive Levels and Events in the Athletes' Psychological Competitive Ability. Journal of health science, 22, 109-120. (In Japanese).

[3] Schurr, K.T., Ashley, M.A. and Joy, K.L. (1977) A Multivariate Analysis of Male Athlete Personality Characteristics: Sport Type and Success. Multivariate Experimental Clinical Research, 3, 53-68.

[4] Okamoto, M., Takatsu, H. and Terada, Y. (1998) A Research of Trait Phychological-Competitive Ability for College Rugby Players: About Experience, Balance and Beginning Time. Bulletin of Aichi Institute of Technology. Part A, 33, 85-88. (In Japanese).

[5] Minouchi, Y. (2013) Athletic Characteristics and Psychological Factors in Union Rugby Football: Psychological Factors for Individuals. Hokusei Review, the School of Humanities, 50, 45-54. (In Japanese).

[6] Maekawa, N., Ito, K., Ishii, K., Koshino, T., Yazaki, R., Tamura, M. and Hirose, N. (2014) A 
Study of Validation of Competitive Abilities Scale of Judo Competitors by Using AHP. Research Journal of Budo, 47, 1-8. (In Japanese).

[7] Saaty, T.L. (1980) The Analytic Hierarchy Process. McGraw-Hill, New York.

Submit or recommend next manuscript to SCIRP and we will provide best service for you:

Accepting pre-submission inquiries through Email, Facebook, LinkedIn, Twitter, etc.

A wide selection of journals (inclusive of 9 subjects, more than 200 journals)

Providing 24-hour high-quality service

User-friendly online submission system

Fair and swift peer-review system

Efficient typesetting and proofreading procedure

Display of the result of downloads and visits, as well as the number of cited articles

Maximum dissemination of your research work

Submit your manuscript at: http://papersubmission.scirp.org/

Or contact jss@scirp.org 